\title{
Removal of Nitrogen and Phosphorus from Animal and Municipal Wastewaters as Dittmarite
}

\author{
Asmare Atalay, Brodie Whitehead, Oluwatomisin Oyewole and Zatima Brown \\ Agricultural Research Station, Virginia State Unviersity, Petersburg, Virginia 23806, USA
}

\begin{abstract}
Phosphorus and nitrogen are known causes of eutrophication in rivers, lakes streams and estuaries. The sources of these nutrients are diverse and they include chemical fertilizers, CAFOs (Confined Animal Feeding Operations), land application of animal and municipal as well as industrial wastewaters. Application of manure slurries to crop land beyond allowable limits could result in high levels of phosphorus and nitrogen in runoff that negatively impact aquatic animals. Municipal wastewater treatment plants are setup to remove these nutrients from domestic and industrial wastewater through a network of treatment processes. Controlling the discharge of phosphorus and nitrogen in wastewater is a key factor in preventing eutrophication. This paper presents work done to enhance a chemical precipitation process that removes over $90 \%$ of dissolved phosphorus and nearly $20 \%$ of dissolved nitrogen from both synthetic and municipal wastewaters. The objective of the study is to remove nitrogen and phosphorus from wastewater as dittmarite, a value-added mineral fertilizer found in nature. A laboratory procedure was developed that generated significant quantities of dittmarite from various wastewaters. Pure dittmarite contains nitrogen, phosphorus and magnesium in approximate molar ratios of 1:1.2:1.2 that can support plant growth. It is produced as a wet precipitate from chemical reactions that occur in the wastewater treatment process; it can be dried for proper handling and utilization. Municipal wastewater treatment plants, high volume fish producers, CAFOs and individual rural homeowners could all benefit from this technology for on-site removal of nitrogen and phosphorus from produced wastewaters.
\end{abstract}

Key words: Dittmarite, precipitation, wastewater, pilot-scale.

\section{Introduction}

Phosphorus in nature exists as phosphates with different oxidation states. The four major types are: $\mathrm{PO}_{4}{ }^{3-}, \mathrm{HPO}_{4}{ }^{2-}, \mathrm{H}_{2} \mathrm{PO}_{4}{ }^{-}$and $\mathrm{H}_{3} \mathrm{PO}_{4}$. These species are present in equilibrium with each other from low to high $\mathrm{pH}$ as written, respectively. Their availability in aqueous solutions is, therefore, $\mathrm{pH}$ dependent. Since they are all soluble in water, they are prone to contribute to eutrophication. Phosphate species can also bind to soil particles and organic debris to remain in sediments for a long time or until changes in $\mathrm{pH}$ dislodging them from their binding sites [1]. Nitrogen also exists in different oxidations states, of which $\mathrm{NO}_{3}{ }^{-}, \mathrm{NO}_{2}{ }^{-}$and $\mathrm{NH}_{4}{ }^{+}$are significant in eutrophication. The origins of nitrogen and phosphorus species indicated above are both organic and inorganic

Corresponding author: Asmare Atalay, Ph.D., research professor, main research fields: soil chemistry and environmental science. fertilizers. From the organic sources, both nutrient elements are transformed by soil microorganisms acid phosphatase [2] and urease [3], nitrosomonas and nitrobacter [4]. When nitrogen is present in wastewater as $\mathrm{NH}_{4}{ }^{+}$and phosphorus as $\mathrm{PO}_{4}{ }^{3-}, \mathrm{HPO}_{4}{ }^{2-}$, or $\mathrm{H}_{2} \mathrm{PO}_{4}^{-}$, in the presence of magnesium $\left(\mathrm{Mg}^{2+}\right)$ and the right $\mathrm{pH}$ conditions, the resulting chemical reaction forms dittmarite or struvite depending on extent of hydration.

Dittmarite was first discovered by a Scottish Scientist, Robert Dittmar who noticed the chemical in wastewater and in drier parts of bat guano [5]. The hexahydrate form of dittmarite is known as struvite, which has been considered a nuisance in wastewater treatment plants as it accumulated in wastewater pipes thereby restricting flow at the elbow joints. Prior to the 1970s, when phosphates were the main ingredients of laundry detergents, it was the main source of phosphorus in wastewater. Later, as EPA 
(Environmental Protection Agency) began restricting the use of phosphate detergents, the sources of nitrogen and phosphorus in wastewater began to shift towards a new paradigm. Use of phosphorus and nitrogen enriched feeds in CAFOs (Confined Animal Feeding Operations), land application of animal manure and chemical fertilizers on agricultural land, and municipal as well as industrial wastewaters, all became contributors to the eutrophication of surface waters. In view of this, EPA once again began regulating the amount of nitrogen and phosphorus that may enter surface waters from these sources. Application of manure slurries on crop land was also regulated by state and federal agencies. Use of fertilizer sources beyond allowable limits could result in high levels of phosphorus and nitrogen in runoff that negatively impact aquatic animals. Municipal wastewater treatment plants are setup to remove these nutrients from domestic and industrial wastewater through a network of treatment processes. Thus, controlling the discharge of phosphorus and nitrogen in wastewater is a key factor in preventing eutrophication.

Struvite is an orthorhombic crystalline structure that consists equal amounts of nitrogen, phosphorus and magnesium [6]. Struvite solubility decreases with increasing $\mathrm{pH}$ up to $\mathrm{pH}$ of 9.0, beyond which its solubility increases [7]. The standard method of phosphorus removal from wastewater involves chemical and biological treatments [8, 9]. However, recently the chemical process of removing phosphorus in conjunction with nitrogen from wastewater as struvite has gained attention [10, 11]. Authors' recent research has revealed that these nutrient elements can be removed as dittmarite, the monohydrate form of struvite. The process involves application of heat to the precipitate until all the water has been driven out. The dry form of struvite or dittmarite is easier to handle, transport and spread in agricultural fields. In wastewaters that have low level of nitrogen, precipitation of dittmarite from wastewater has been enhanced with the addition of small quantities of nitrogen from organic sources. In this case, all ingredients necessary to form dittmarite were present in wastewater. Therefore, given the right environmental conditions, dittmarite could precipitate effectively in large quantities. Dittmarite can be used as a slow release fertilizer $[12,13]$ providing the three important macronutrients (nitrogen, phosphorus and magnesium) for plant growth.

\section{Materials and Methods}

\subsection{Benchtop Preliminary Assessment}

One-gallon wastewater samples were obtained from Central Wastewater Authority, Petersburg, VA; Chesterfield County Utilities Department; Chesterfield, Virginia; Blue Ridge Aquaculture, Martinsville Virginia; Martinsville Aquaculture; and from three locations on the Appomattox River near Petersburg, Virginia. The initial concentrations of nitrogen and phosphorus were determined in the raw wastewater and river water samples. Dittmarite precipitation was achieved by adjusting the $\mathrm{pH}$ of the solution to 5.0 and incrementally adding $1 \mathrm{M} \mathrm{MgCl}_{2}$ while stirring. The $\mathrm{pH}$ was raised until precipitation was noticed and continued until pH 9.0 was reached. Between these $\mathrm{pH}$ ranges, all the nitrogen and phosphorus in the sample was precipitated as dittmarite. Final concentrations of nitrogen and phosphorus were determined after dittmarite precipitation. Similar procedures were followed using on-the-shelf chemicals to precipitate pure dittmarite.

\subsection{Pilot-Scale Assessment}

The pilot-scale assessment consists of construction of a portable unit (Fig. 1) that can be hitched or mounted on the back of a truck and transported for on-site demonstration of the technology. The unit consists of a 30-gallon tank with inlet on top for wastewater addition and outlet below for dittmarite removal. Several small holes were bored on the tank for stirrer, pH-probe and solvent inlets. Initially 25 


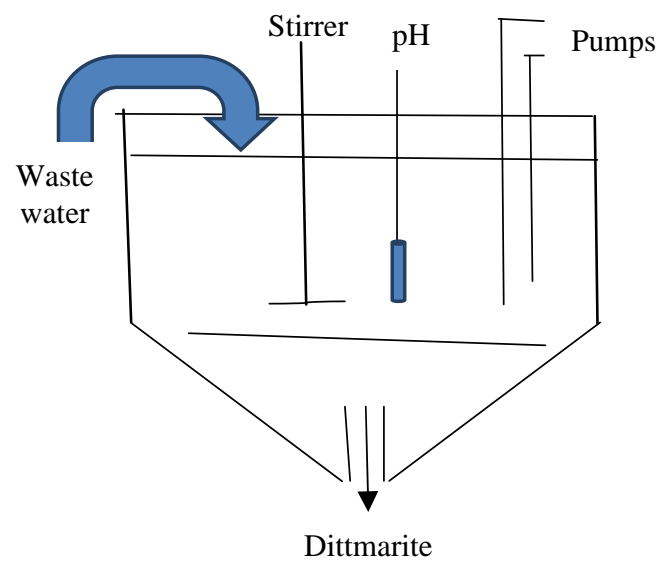

Fig.1 A pictorial view for pilot-scale production of dittmarite from wastewater.

gallons of fish wastewater was used for demonstration of the technology in a field scale. The procedure used for precipitation of dittmarite was the same as described in the bench-scale. Dittmarite was removed from the bottom of the tank as a white solid and it was air-dried and stored for use as a fertilizer supplement. Similar small studies have removed phosphorus and nitrogen from animal and municipal wastewaters [14, 15].

\section{Results and Discussion}

This research developed and enhanced a chemical precipitation method that removes over $90 \%$ of phosphorus and nearly 20\% of nitrogen from both synthetic and municipal wastewaters. The objective of the study is to remove nitrogen and phosphorus from wastewater as dittmarite, a value-added mineral fertilizer found in nature. A laboratory procedure was developed that generated significant quantities of dittmarite from various wastewaters. Pure dittmarite contains nitrogen, phosphorus and magnesium in molar ratios of 1:1.2:1.2, respectively. These elements as present in such ratios supply sufficient nutrients appropriate for plant growth. The precipitation of dittmarite is significantly related to the $\mathrm{pH}$ of the media and the availability of magnesium in the wastewater.
Usually sufficient amount of magnesium must be added to the wastewater in order to effectively precipitate dittmarite. The $\mathrm{pH}$ must also be kept between 8.0 and 9.0 to capture nitrogen, an important ingredient for dittmarite formation. Fig. 2 conveniently represents the trend of nitrogen availability for dittmarite precipitation at various stages as $\mathrm{pH}$ is raised from low to high. The maximum precipitation of pure dittmarite is achieved when all necessary ingredients are present in the wastewater. Other chemicals have been used to precipitate dittmarite from animal manures [15]. Dittmarite is produced as a wet precipitate from the chemical reactions that occur in the wastewater treatment process; it can be dried for proper handling and utilization. Municipal wastewater treatment plants, high volume fish producers and CAFOs can all benefit from the application of this technology for on-site removal of nitrogen and phosphorus from their respective wastewaters. Bench-scale studies have indicated that wastewater from municipal wastewater treatment plants and high capacity fish producers all contain significant levels of nitrogen and phosphorus. Therefore, on-site removal of these elements could reduce their contributions to eutrophication of receiving waterbodies. Table 1 provides dittmarite data obtained from various wastewater sources and river water samples. As shown, the municipal wastewater sources gave more dittmarite per volume of wastewater compared to the fish wastewater samples. This is apparent from the high levels of nitrogen and phosphorus present in these samples. Compared to the other sources, municipal and fish wastewaters showed more nitrogen and phosphorus, which led to the precipitation of higher amount of dittmarite upon addition of excess magnesium. The dittmarite was obtained by processing $250 \mathrm{~mL}$ of wastewater from each source and drying it in an oven overnight at $105^{\circ} \mathrm{C}$. 


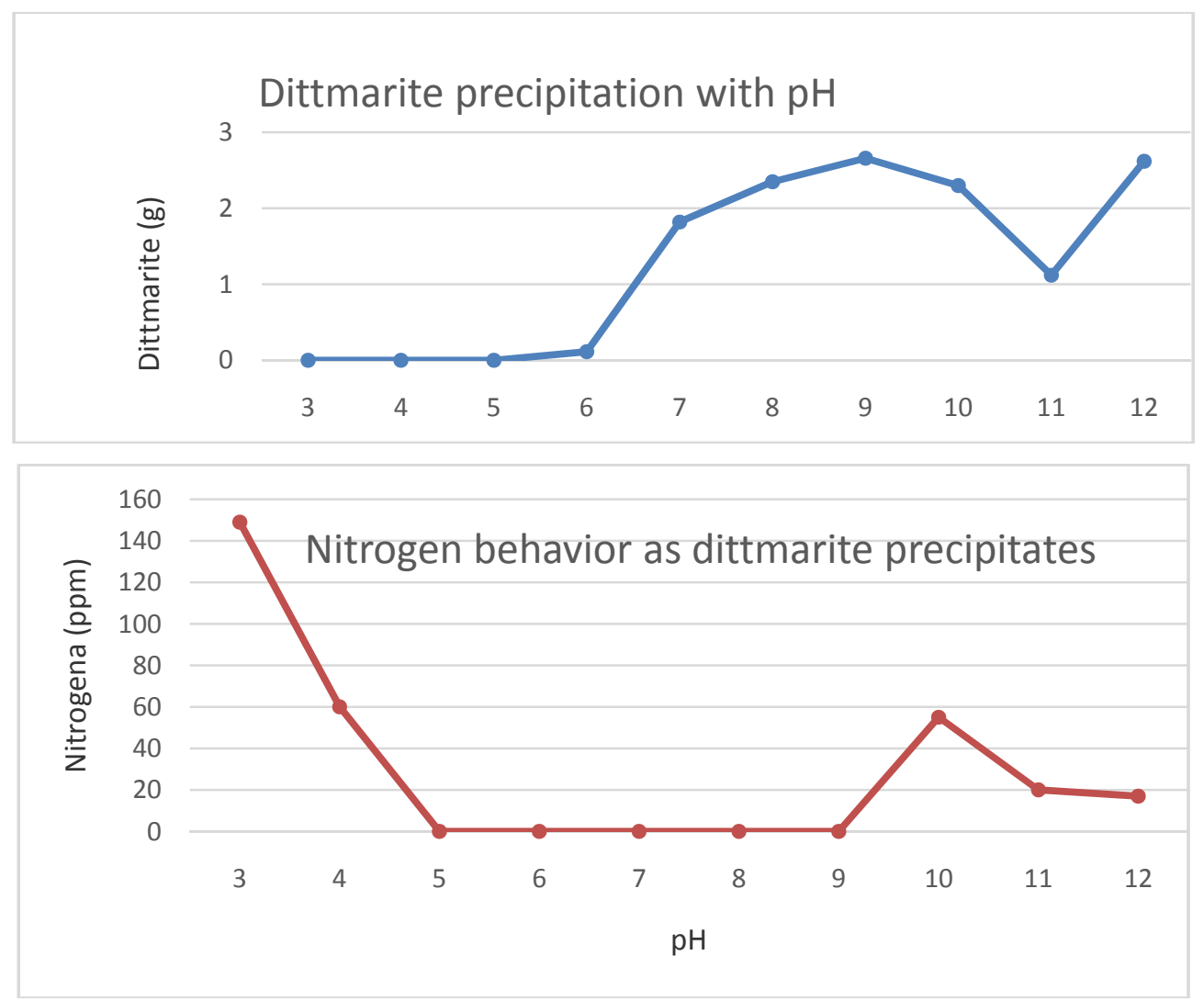

Fig. 2 The relationship between dittmarite formation and nitrogen disappearance as pH is raised from low to high.

Table 1 Phosphorus and nitrogen concentrations and their percent removal as dittmarite from various wastewater sources in a bench-scale study.

\begin{tabular}{llllllll}
\hline Wastewater sources & \multicolumn{3}{c}{ Phosphorus (ppm) } & \multicolumn{3}{c}{ Nitrogen (ppm) } & \multicolumn{2}{c}{ Dittmarite (g) } \\
\cline { 2 - 7 } & Before & After & \% Removed & Before & After & \% Removed \\
\hline Central WW & 6.81 & 1.07 & 84.3 & 157.43 & 44.74 & 71.58 & 14.76 \\
Chesterfield WW & 13.57 & 3.58 & 73.6 & 139.28 & 97.56 & 29.95 & 11.86 \\
Blue Ridge fish & 4.75 & 1.66 & 65.0 & 55.11 & 21.51 & 60.97 & 3.94 \\
Martinsville fish & 3.24 & 0.99 & 69.4 & 275.28 & 247.99 & 9.91 & 5.62 \\
Appomattox 1 & 0.26 & 0.24 & 7.7 & ND & ND & 0 & $4.94^{*}$ \\
Appomattox 2 & 0.83 & 0.39 & 53.0 & ND & ND & 0 & $4.91^{*}$ \\
Appomattox 3 & 2.92 & 0.54 & 81.5 & ND & ND & 0 & $3.41^{*}$ \\
\hline
\end{tabular}

Note: ND = not detected; ${ }^{*}$ Non-dittmarite precipitation of phosphorus from river water at higher pH levels; Appomattox 1, 2 and 3 represent different sampling locations along the river; $\mathrm{WW}=$ waste water.

In order to verify that dittmarite was the one that precipitated from the various wastewaters, authors used electron XRD (Diffraction X-Ray) and compared it with pure dittmarite which was made using over-the-counter chemicals from the laboratory (Figs. 3 and 4). It appears that the XRD from the wastewater sample had a small amount of sulfur, which appears as impurity. However, the elemental contents ( $\mathrm{Mg}$ and $\mathrm{P}$ ) were present in approximately the same ratios in both samples. Nitrogen would not be expected to show in the XRD, since it volatilizes at high temperatures. 


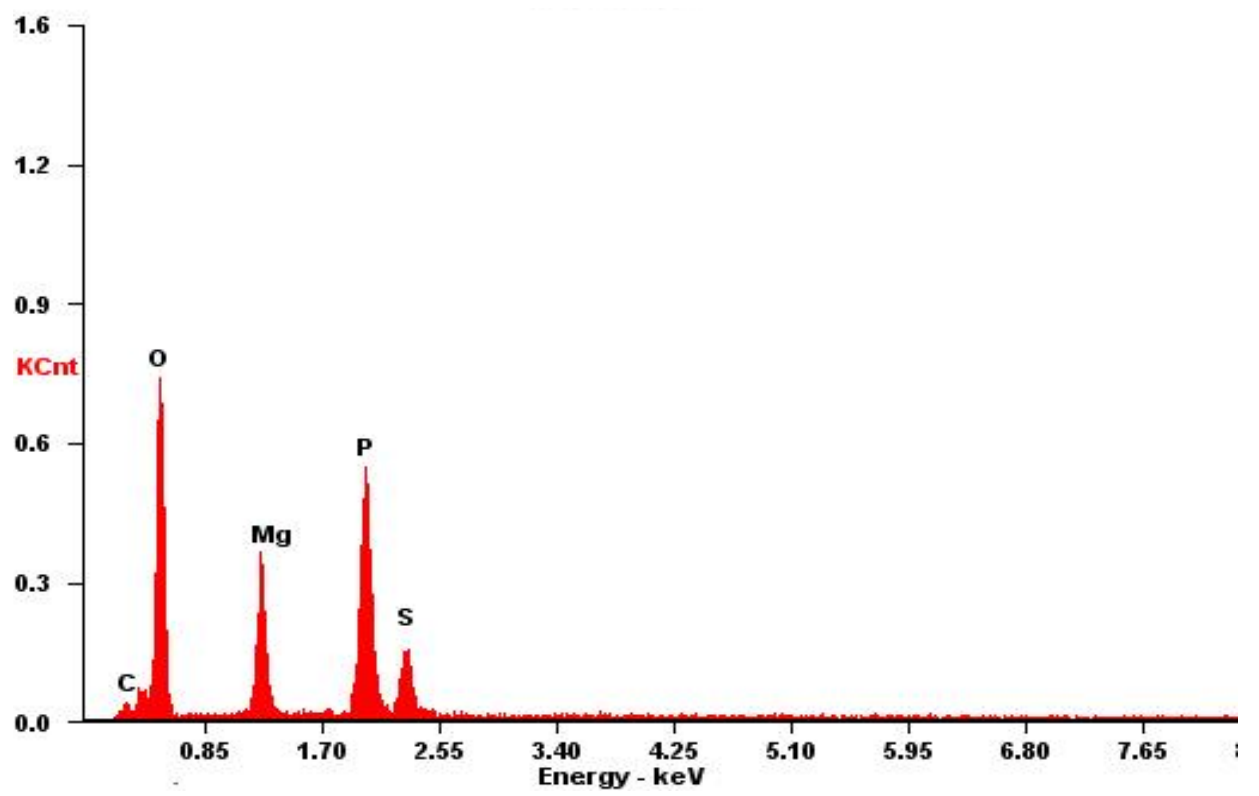

Fig. 3 EDX (Electron Diffraction X-ray) of synthesized dittmarite.

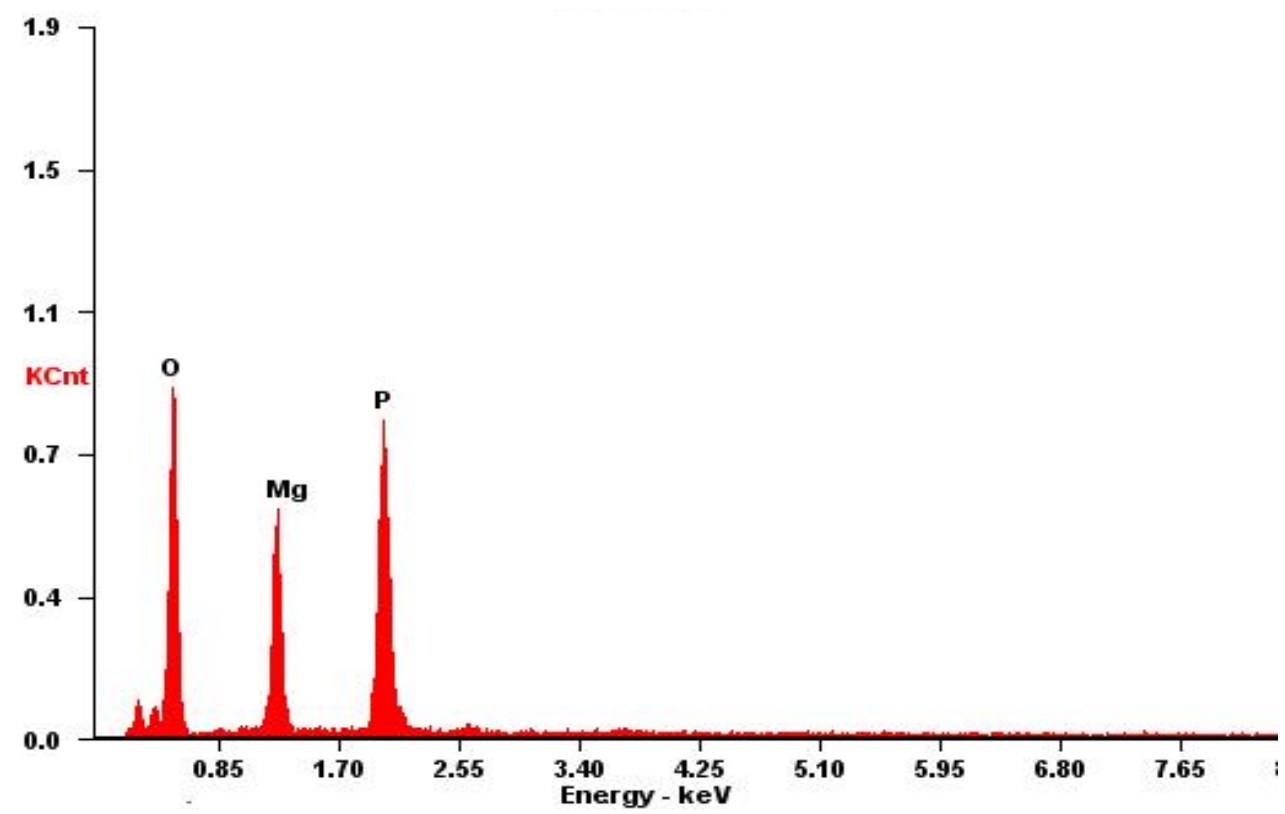

Fig. 4 EDX of pure dittmarite.

\section{Conclusion}

Dittmarite is a naturally existing mineral that contains nitrogen, magnesium and phosphorus in equal proportions. The hexahydrate form of dittmarite is called struvite, which accumulates in wastewater pipes and restrictes flow, especially at the elbow joints. Both dittmarite and struvite are value-added products that can be used to supplement fertilizers; they provide sufficient amounts of macro and micro elements for plant growth. This research demonstrated that mall-scale pilot plants can be installed at various locations in wastewater sources to reduce nitrogen and phosphorus overload in rivers, lakes and bays. Confined animal operators, especially swine and cattle production sites, large-scale fish producers and septic tanks in rural communities can benefit from this technology. 


\section{References}

[1] Atalay, A., Bronick, C., Beaker, K., and Whitehead, B. 2015. "Assessment on the Stability and Speciation of Phosphorus in River Sediments.” The Global Environmental Engineers 2: 79-86.

[2] Atalay, A., and Blanchard, R. W. 1984. "Evaluation of Methane Generator Sludge as a Soil Amendment.” $J$. Environ. Qual. 13 (3): 341-4.

[3] Atalay, A., and Blanchard, R. W. 1988. "Urease Activity in Soil Amended with Methane-Generator Sludge." Biological Wastes 26 (1): 49-58.

[4] Alexander, M. A. 1977. Introduction to Soil Microbiology (2nd ed.). John Wiley \& Sons New York, 128-246.

[5] Sarkar, A. K. 1991. "Hydration/Dehydration Characteristics of Struvite and Dittmarite Pertaining to Magnesiium and Ammonium Phosphate Cement Systems.” Journal of Material Science 26 (9): 2514-8.

[6] Lee, S. I., Weon, S. Y., Lee, C. W., and Koopman, B. 2003. "Removal of Nitrogen and Phosphate from Wastewater by Addition of Bittern.” Chemosphere 51 (4): 265-71.

[7] Michalowiski, T., and Pietrzyk, A. 2006. "A Thermodynamic Study of Struvite + Water System.” Talanta 68 (3): 594-601.

[8] Burns, R. T., Moody, L. B., Walker, F. R., and Raman, D. R. 2001. "Laboratory and In-situ Reductions of Soluble Phosphorus in Swine Waste Slurries.” Environ. Tech. 22 (11): 1273-8.
[9] Sotirakou, E., Kladitis, G., Diamantis, N., and Grigoropoulou, H. 1999. “Ammonia and Phosphorus Removal in Municipal Wastewater Treatment Plant with Extended Aeration.” Global Nest: The Int. J. 1 (1): 47-53.

[10] Liberti, L., Limoni, N., Lopez, A., Passino, R., and Boari, G. 1986. "The $10 \mathrm{~m}^{3} \cdot \mathrm{h}^{-1}$ RIM-NUT Demonstration Plant at West Bari for Removing and Recovering $\mathrm{N}$ and $\mathrm{P}$ from Wastewater.” Water Res. 20 (6): 735-9.

[11] Parson, S. A. 2001. "Recent Scientific and Technical Developments: Struvite Precipoitation.” CEEP Scope Newslett 41: 15-22.

[12] Wrigley, T. J., Webb, K. M., and Venkitachalm, H. 1992. "A Laboratory Study of Struvite Precipitation after Anaerobic Digestion of Piggery Wastes.” Biores. Technol. 41 (2): 117-21.

[13] Zhang, T., Bowers, K. E., Harrison, J. H., and Chen, S. 2010. "Releasing Phosphorus from Calcium for Struvite Fertilizer Production from Anaerobically Digested Dairy Effluent.” Water Environ. Res. 82 (1): 34-42.

[14] Battistoni, P., Fava, G., Pavan, P., Musacco, A., and Cecchi, F. 1997. "Phosphate Removal in Anaerobic Liquors by Struvite Crystallization without Addition of Chemicals: Preliminary Results.” Water Res. 31 (11): 2925-9.

[15] Burns, R. T., and Moody, L. B. 2002. "Phosphorus Recovery from Animal Manures Using Optimized Struvite Precipitation." Proc. of Coagulants and Flocculants: Global Market and Technical Opportunities for Water Treatment Chemicals, May. 